\title{
EXPERIMENTAL MODEL OF WIND TURBINE WITH VERTICAL AXIS, MULTI-STOREY AND WITH 2 PAIRS OF BLADES ON LEVEL COUPLED AERODYNAMIC
}

\author{
Nelu CAZACU \\ "Dunarea de Jos" University of Galati, Romania \\ e-mail: nelu.cazacu@ugal.ro
}

\begin{abstract}
The concept presented in this paper tries to solve the torque uniformity of the wind turbine with vertical axis. The concept of multi-stage S-rotor without angular delay is used. At the floor level, two pairs of blades are used and the aerodynamic coupling of the opposing blades by overlapping. The tests were carried out in the wind tunnel at wind speeds of up to $9 \mathrm{~m} / \mathrm{s}$ and the use of data acquisition systems. The results confirm the favourable behaviour of the experimental model and the validity of the concept.
\end{abstract}

KEYWORDS: VAWT, Savonius type, 2 pair of blades, multistage

\section{Introduction}

The vertical axis wind turbine Savonius type is one of the most known turbines due to its constructive simplicity [1]. Constructively, the Savonius turbine has in its simplest structure a pair of blades, hemispherical or semi-cylindrical, placed symmetrically with respect to a vertical axis of rotation. The semi-cylindrical blades have the axis of the cylinder parallel to the axis of rotation (Fig. 1) with the so-called active stroke from 0 to 180 degrees, and the reverse stroke from 180 to 360 degrees (Fig. 2).

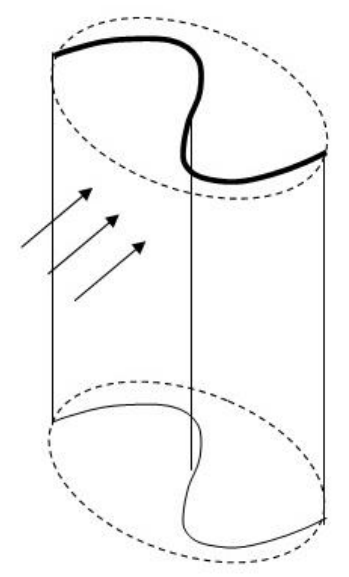

Fig. 1. The rotation motion occurs due to the different behaviour of the blade against the airflow
The aerodynamic resistance that the paddle opposes is different and can be found in the so-called coefficient of resistance (CD), which has a value of 1.2 for the active cup, and a value of 0.3 for the resistant cup.

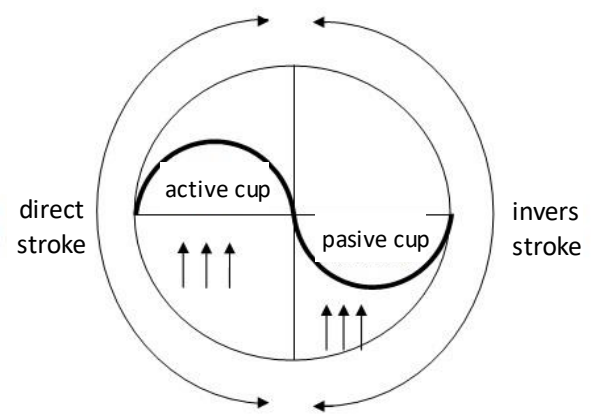

Fig. 2. Rotation motion of the "S-rotor" turbine

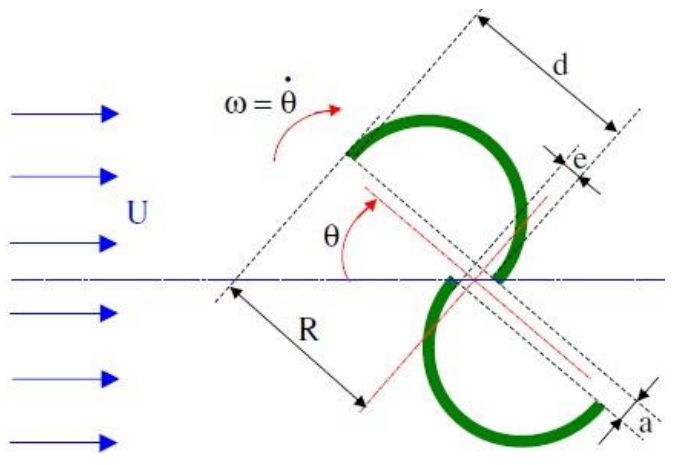

Fig. 3. "S-Rotor"(Savonius Wind Turbine) [2] 
By integrating the pressure exerted on the surface of the blade, a resultant force is obtained that differs for each of the two blades, depending on the position relative to the zero point. The force differences between the active and the resistant race give rise to a rotating torque.

A rotor is called a conventional Savonius rotor if the geometric parameters $a$ and $e$ are equal to 0 and respectively, d/6. (Fig. 3).

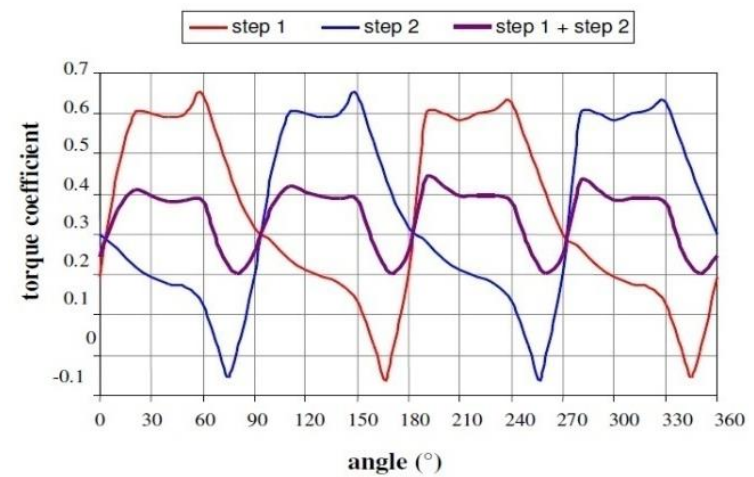

Fig. 4. 360-degree torque variation [2]

The main disadvantage of the 2-blade Savonius vertical axis wind turbine is the unevenness of the rotation torque which is shown schematically in Fig. 4 to the 360 -degree variation of the torque.

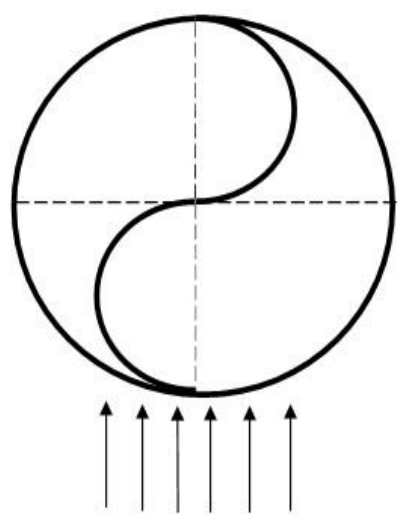

Fig. 5. The position of the cups from the wind direction when the couple is very small

There is a point where the couple is very small, that is when the blades are in the wind direction, a situation shown in Fig. 5.

In this case, the torque may be very small and the wind turbine may not start. If the wind is coupled to a mechanical load, respectively a generator, the unevenness of the couple is found in the unevenness of the power at the axis that the generator can cut.

\section{Notations}

$\sigma$ - Indices of solidities $\mathrm{v}$ - wind speed, $\mathrm{m} / \mathrm{s}$

$\rho$ - air density, $\mathrm{kg} / \mathrm{m}^{3}$

L - mechanical work, J

$\mathrm{x}$ - distance, $\mathrm{m}$

$\mathrm{P}$ - power, $\mathrm{W}$

$\mathrm{V}$ - air volume, $\mathrm{m}^{3}$

$\Delta \tau$ - time interval, $\mathrm{s}$

A - swept aria, $\mathrm{m}^{2}$

CD - drag coefficient

$\omega$ - angular speed, radians / s

g - gap, mm; (a)

o - overlap, mm; (e)

$\mathrm{d}$ - cup base diameter, $\mathrm{m}$

$\mathrm{R}-\mathrm{S}$ rotor radius, $\mathrm{m}$

$\theta$ - instantaneous angle, degree

$\mathrm{F}$ - force, $\mathrm{N}$

$\Delta \tau$ - time interval, $\mathrm{s}$

$\mathrm{m}$ - mass of air, $\mathrm{kg}$

$\mathrm{V}$ - air volume, $\mathrm{m}^{3}$

L - Mechanical work, N

\section{Abbreviations}

HAWT - Horizontal Axis Wind Turbine microWT - micro Wind Turbine VAWT - Vertical Axis Wind Turbine LED - Light Emitting Diode

Different conceptual models of vertical-axis wind turbine can be developed with improved starting torque:

- The simplest method of uniformity of torque and power respectively to the shaft is the use of a flywheel, which, however, has the disadvantage of increasing turbine inertia and a more difficult start;

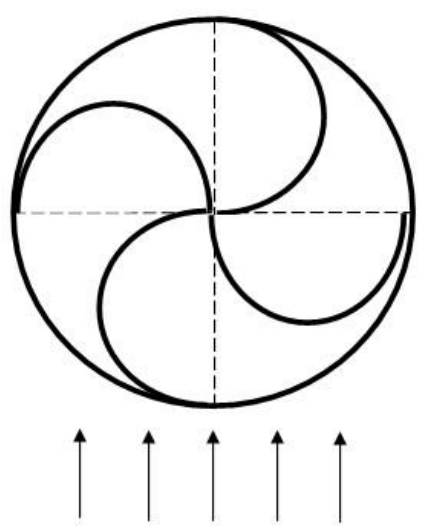

Fig. 6. Wind turbine Savonius type with 4 blades

- Another often used variant is to increase the number of wind blades to at least 4 (2 pairs). (Fig. 6);

- Construction of stages (Fig. 7). In this way, there is always at least one pair of blades in a 
favourable position for which between forces and torque is large;

- Using twisted blades and approaching the vertical model Helix VAWT (3). This is achieved by dividing the blades into a number of $\mathrm{n}$ floors and offset each floor by 360 per n degrees. At this type of wind, the torque uniformity is high (the higher the $n$ ). In contrast, the degree of difficulty for the construction of the wind turbine increases (4).

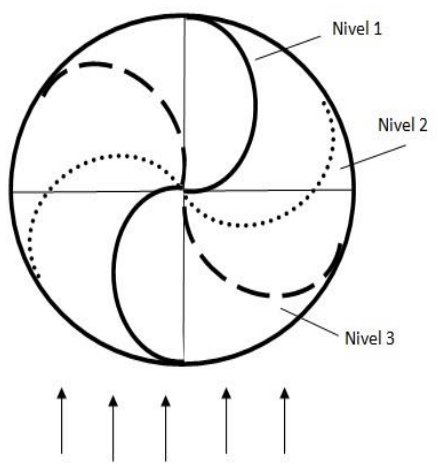

Fig. 7. Wind turbine type Savonius with 3 stage

The conceptual model is based on the idea that by using an aerodynamic profile commonly used in the aeronautical industry and HAWT, the operation of a Savonius type wind turbine can be improved by improving the operation of the wind turbine at the socalled "dead end"S (when the axis of the Savonius type turbine blades). Is in the same direction as the difference wind). Making floors in this way, there is always at least one pair of blades in a favourable position for which the difference between forces and torque is large.

There are several mathematical models to calculate the wind energy. The dynamic pressure of the wind, due to its displacement, is calculated according to the equation:

$$
p=\rho \frac{v^{2}}{2}
$$

where: $\rho$ - air density, $\mathrm{kg} / \mathrm{m} 3$; $\mathrm{v}$ - wind speed, $\mathrm{m} / \mathrm{s}$.

The larger the surface on which the wind acts, the greater the force produced by it [5]. In contact with a surface, the wind is broken, the kinetic energy transforming into potential pressure energy, respectively mechanical energy transferred to the surface that realized the braking. The force $F$ developed by the wind on a surface $A$ can be calculated:

$$
F=p A
$$

$$
F=\rho \frac{v^{2}}{2} A
$$

Mechanical work $\mathrm{L}$ when moving air over distance $\mathrm{x}$, is calculated by the relation:

$$
\begin{gathered}
L=F X \\
L=\rho \frac{v^{2}}{2} A x
\end{gathered}
$$

The power of the wind, over time $\Delta \mathrm{t}$ is calculated with the relation:

$$
P=\frac{L}{\Delta \tau}
$$

and by replacement:

$$
P=\rho \frac{v^{2}}{2} A \frac{x}{\Delta \tau}
$$

Where $\mathrm{x} / \Delta \tau=\mathrm{V}$ is wind speed, and relation became:

$$
P=\rho \frac{v^{3}}{2} A
$$

At the same distance $\mathrm{x}$ the volume of air moved is:

$$
V=A x
$$

From which results the mass of air that moves under the action of the wind determined with the relations:

$$
\begin{aligned}
& m=\rho V \\
& m=\rho A x
\end{aligned}
$$

Where the kinetic energy of the air mass is calculated with the relations:

$$
\begin{gathered}
E c=m \frac{v^{2}}{2} \\
E c=\frac{1}{2} \rho A x v^{2}
\end{gathered}
$$

Or knowing that $\mathrm{x}=\mathrm{v} \tau$ results:

$$
E c=\frac{1}{2} \rho A v^{3} \tau
$$
and Fig. 9.

The experimental models are presented in Fig. 8

Wind Tunnel [6] is the equipment that underlies the measurements made on the experimental models 
of the wind turbines. It is made of plywood, with dimensions $0.5 \mathrm{~m} \times 0.5 \mathrm{~m}$, with a length of equalization area of $2 \mathrm{~m}$ and recording a wind speed between 0 and $9.5 \mathrm{~m} / \mathrm{s}$.

The LCA 6000 anemometer has the following characteristics: measuring range: $0.25 \quad \ldots \quad 30 \quad \mathrm{~m} / \mathrm{s}$, tolerance range: $+/-1 \%,+/-\mathrm{LSD}$, temperature range: $-10{ }^{\circ} \mathrm{C} . . .50{ }^{\circ} \mathrm{C}$, pressure range: 500 mbar...2 bar, integration time measurement: approx. $3 \mathrm{~s}$.

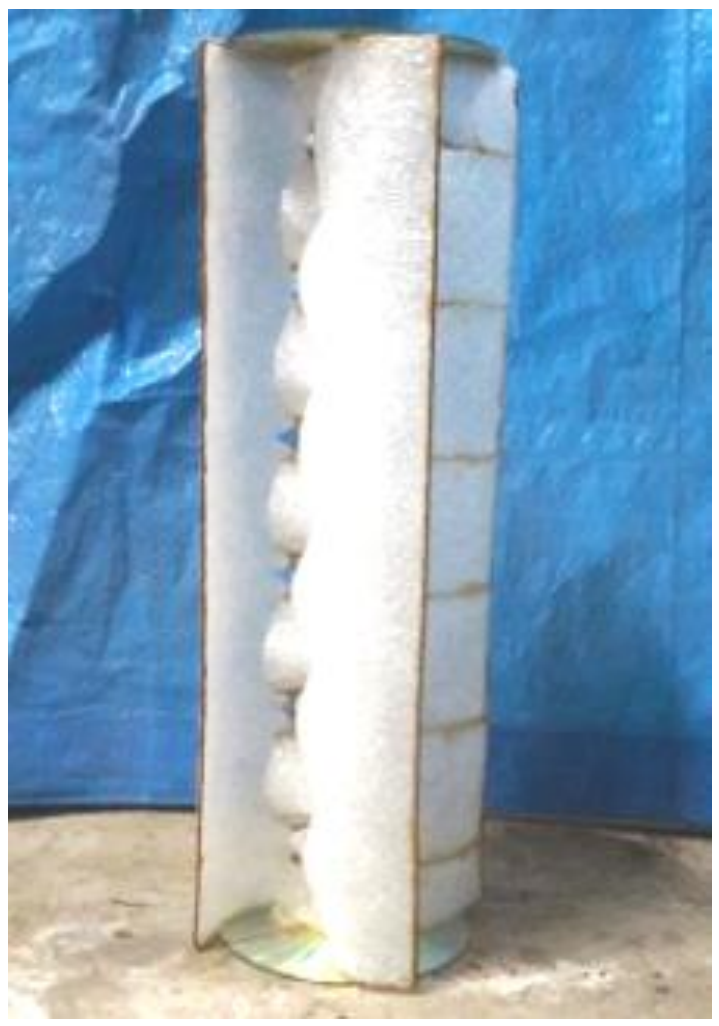

Fig. 8. Experimental model EM-C13

Experimental frame with minimum friction with multiplier and generator made of two steel plates (lower and upper, with dimensions of $450 \times 450 \mathrm{~mm}$, height $480 \mathrm{~mm}$ ), 6 columns (2 working and 4 supporting and stiffening). This framework allows fixing the experimental model and the measurement sensors, but also an easy change of the designed wind models. The models are supported on two $300 \mathrm{x} 40 \mathrm{x}$ $8 \mathrm{~mm}$ sleepers, which are adjusted on the work columns by means of nuts and washers. In the centre of these sleepers bearings and bearing devices are located on the discs of the experimental models. The experiments were carried out in the wind tunnel for the two experimental models and for different mechanical and electrical loads. When testing between peaks the only task acting on the model is friction in bearings (peaks). For the other tests, the model was fixed on the axis of a speed multiplier + DC electric generator, at its output electrical charges
(LED, adjustable load resistance) can be connected. When testing between peaks the only task acting on the model is friction in bearings (peaks). For the other tests, the model was fixed on the axis of a speed multiplier + DC electric generator, at its output electrical charges (LED, adjustable load resistance) can be connected.

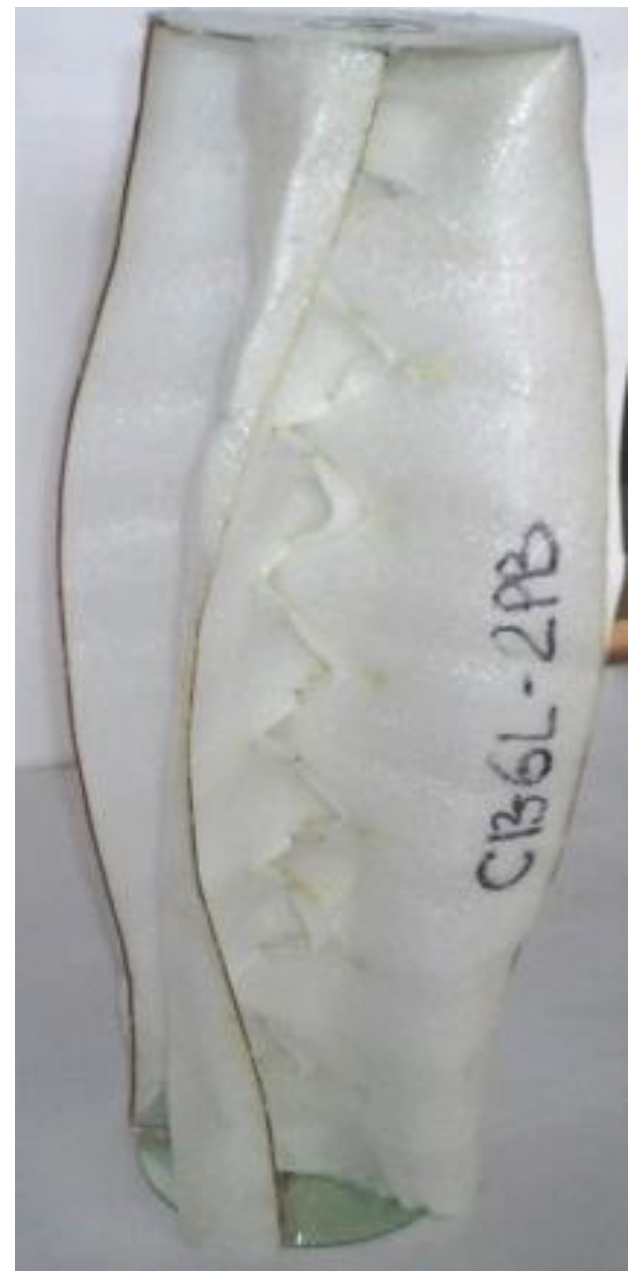

Fig. 9. Experimental model EM-C12

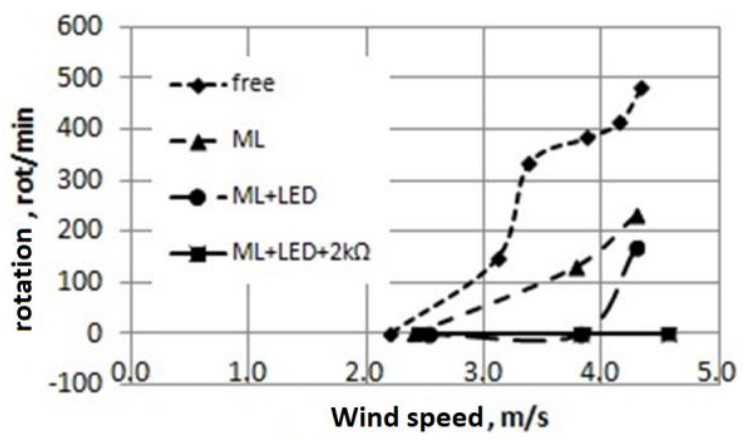

Fig. 10. The influence of wind speed on the speed EM C12 


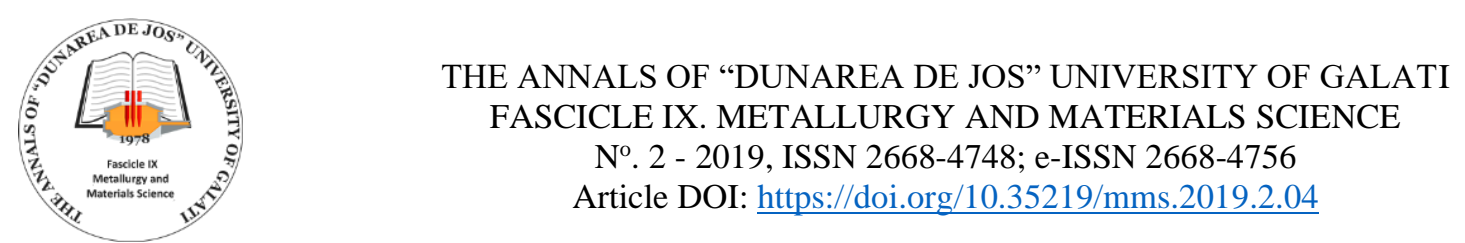

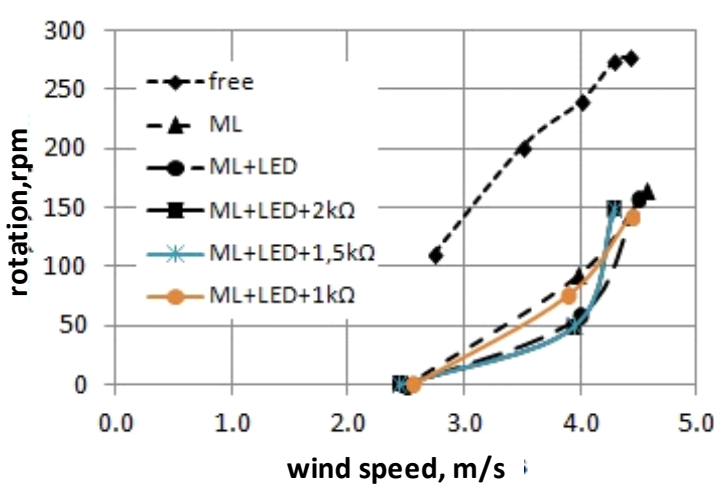

Fig. 11. The influence of wind speed on the speed of EM-CI3

\section{Results and discussions}

The graph in Figure 12. represent the influence of wind speed on the speed of the experimental model EM-CI2 for different load values. The rotations of the blades increase with the increase of the wind speed. When a mechanical load is applied, and gradually increasing its values, a significant decrease in blade speed is observed.

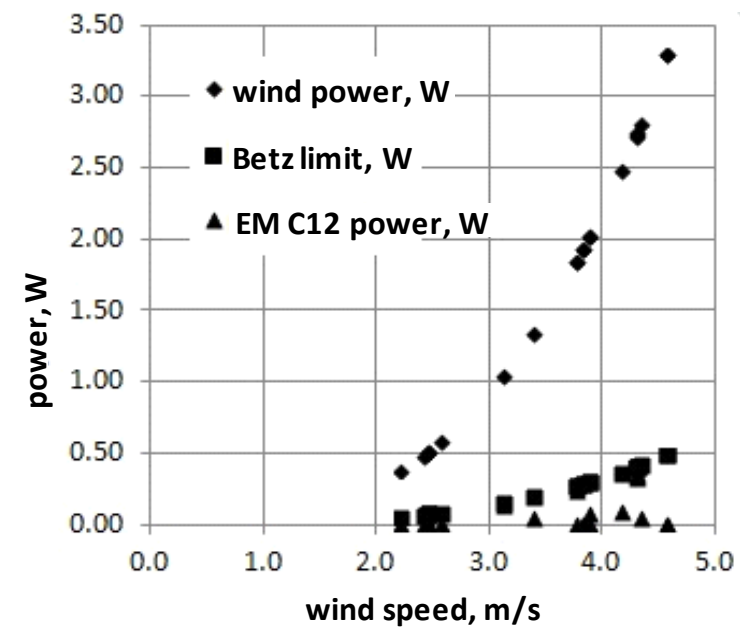

Fig. 12. Variation of powers in the wind speed system (EM-CI2)

In Fig. 15 was showed how the powers in the system vary with the wind speed, for different added load values. Having established the limit of Betz for the experimental model, it is observed that the power EM-CI2 is below this limit, reaching a maximum value of $0.343 \mathrm{~W}$, at a wind speed of $4.3 \mathrm{~m} / \mathrm{s}$, has applied a LED.

The graph in Fig. 13 represent the influence of the specific speed on the Reynolds number for EMC12.

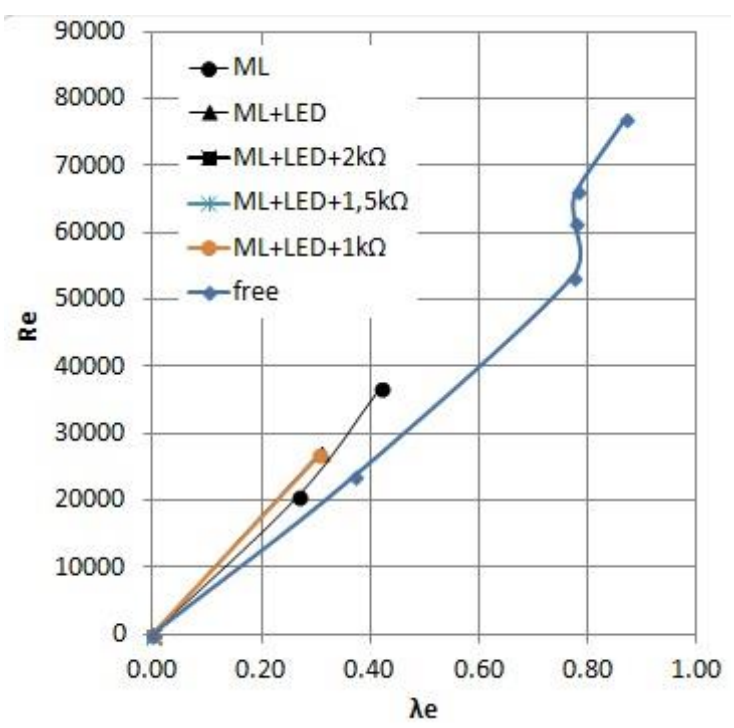

Fig. 13. Reynolds number variation with specific speed for EM C12

In the case of the experimental model $\mathrm{CI} 3$, the graph in Fig. 13 highlights how the wind speed influences the turbine speed in the wind tunnel, at different values of the applied mechanical load.

As the wind speed increases, the rotations of the blades of the experimental model EM-CI3 register a linear increase, if no load is applied to the so-called "idle", reaching a maximum value of 278 rotations per minute, at with a wind speed of $4.4 \mathrm{~m} / \mathrm{s}$. Since it is applied mechanical loads, the rotations decrease, but following the same linear growth curve, as the wind speed increases.

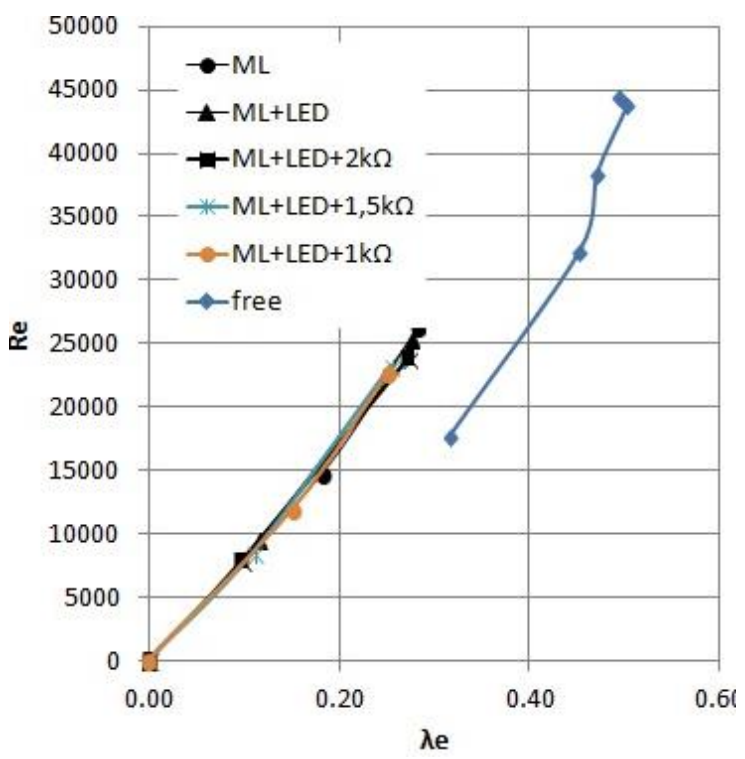

Fig. 14. Reynolds number variation with specific speed for EM C13 
As it has been shown, increasing the wind speed increases its power, implicitly the power of the experimental turbine. Referring to the Betz limit set for the experimental model EM-CI3, it is observed that the turbine is approaching this value very well, reaching a maximum power of $0.405 \mathrm{~W}$ at a wind speed of $4.6 \mathrm{~m} / \mathrm{s}$ but without any applied load. The graph in Fig. 14 shows the influence of the specific speed on the Reynolds number for the experimental model EM-CI3.

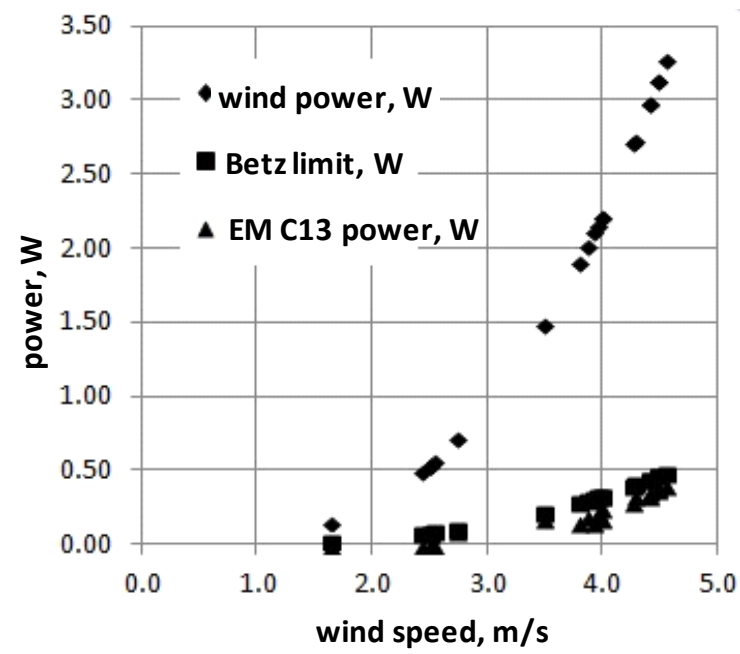

Fig. 15. Variation of powers in the system with the wind speed EM-C13

\section{Conclusions}

- The experimental models realized according to the concept of the theoretical part exposed at the beginning of the work show the validity of applying the aerodynamic profiles to the vertical turbines of the type Savonius.
- The experiments performed on the experimental model CI2 with two blades with aerodynamic profile and coupled (range and overlap), demonstrate the easy passage through the zero point (with a high speed).

- The uniformization of the wind movement is shown by the experimental model CI3, in which the operation is very uniform, due to the combination of the aerodynamic profiles (approximately NACA 4412) at the base of the model, and due to the extended surface in the middle of the model.

- Vertical, 6-level coupling of the pairs of blades allows efficient wind loading and uniformity of torque in operation.

- Testing the experimental model with 6 load levels shows an operation between 2.5 and $4.5 \mathrm{~m} / \mathrm{s}$ wind speed and a decrease in load speed.

- The efficiency of the experimental models reached the maximum value of $13 \%$ for the operation of the model in a hollow, and for $2.7 \mathrm{~m} / \mathrm{s}$ the wind speed.

- The maximum values of $12 \%$ for minimum loads, respectively mechanical loads and leads, and wind speeds exceeding $4 \mathrm{~m} / \mathrm{s}$ were reached.

\section{References}

[1]. Hau Erich, Wind Turbines, Fundamentals, Technologies, Applications, Economics, s.l.: Springer, 2006.

[2]. Menet J. L., Bourabaa N., Increase in a savonius rotor efficiency.

[3]. Saha U. K., Rajkumar M. J., On the performance analysis of Savonius rotor with twisted blades, Renewable Energy, 31, 2006.

[4]. Zigman A., Optimization of a Savonis Rotor Vertical-Axes wind turbine, Massachussets: MIT, 2007.

[5]. Manwell J. V., McGowan J. G., Rogers A. L., Wind Energy Explained. Theory, Design and Application.

[6]. Nelson V., Wind Energy. Renewable Energy and the Environment, s.1.: Taylor \& Francis Group LLC, 2009. 